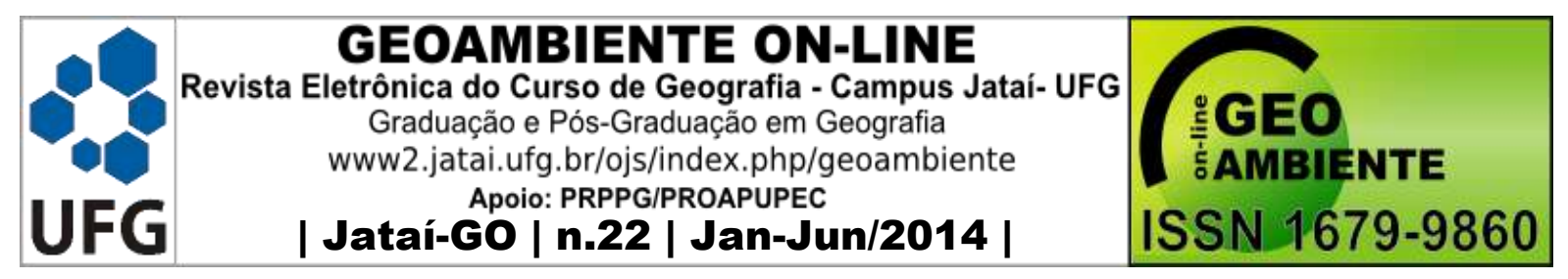

\title{
INFLUÊNCIA DO USO DA TERRA EM VARIÁVEIS LIMNOLÓGICAS NA MICROBACIA HIDROGRÁFICA DO ARROIO ALBERTI - SÃO JOÃO DO POLÊSINE/RS
}

Edison Antonio Alberti' ${ }^{1}$, Waterloo Pereira Filho

(1 - Universidade Federal de Santa Maria, Departamento de Geociências, Mestrando do Programa de Pós-graduação em Geografia, edisonalberti@gmail.com, 2 - Universidade Federal de Santa Maria, Docente, waterloopf@gmail.com)

\section{Resumo}

O objetivo geral deste trabalho é analisar a interação do uso da terra com variáveis limnológicas na microbacia hidrográfica do arroio Alberti, localizado no município de São João do Polêsine / RS. Para atingir este objetivo, o canal principal do rio foi dividido em cinco seções com base na geomorfologia e acesso ao local, a fim de definir os pontos de coleta de água em cada seção. A classificação do uso da terra foi obtida a partir de uma imagem do sensor ETM+ do satélite LANDSAT 7. Para a identificação do uso da terra foram definidas as seguintes classes: floresta, campo, agricultura, água e área urbana. As variáveis limnológicas utilizadas foram: condutividade elétrica, $\mathrm{pH}$, temperatura da água e total de sólidos em suspensão. As análises destas variáveis permitiram identificar que os diferentes usos da terra proporcionam ambientes diferenciados ao longo do arroio com reflexo em todas as variáveis limnológicas. As variáveis $\mathrm{pH}$ e total de sólidos em suspensão foram mais intensamente dependente do uso da terra. Os valores mais alterados destas variáveis foram constatados justamente nos pontos amostrais localizados junto ao núcleo urbano de São João do Polêsine, reflexo das intervenções antrópicas.

Palavras-chave: Limnologia, Sensoriamento Remoto, Microbacia Hidrográfica

\author{
Abstract \\ INFLUENCE OF LAND USE ON LIMNOLOGICAL VARIABLES IN THE \\ WATERSHED OF ALBERTI CREEK - SÃO JOÃO DO POLÊSINE/RS
}

\footnotetext{
Artigo recebido para publicação em 05 de Março de 2014 Artigo aprovado para publicação em 08 de Junho de 2014
} 


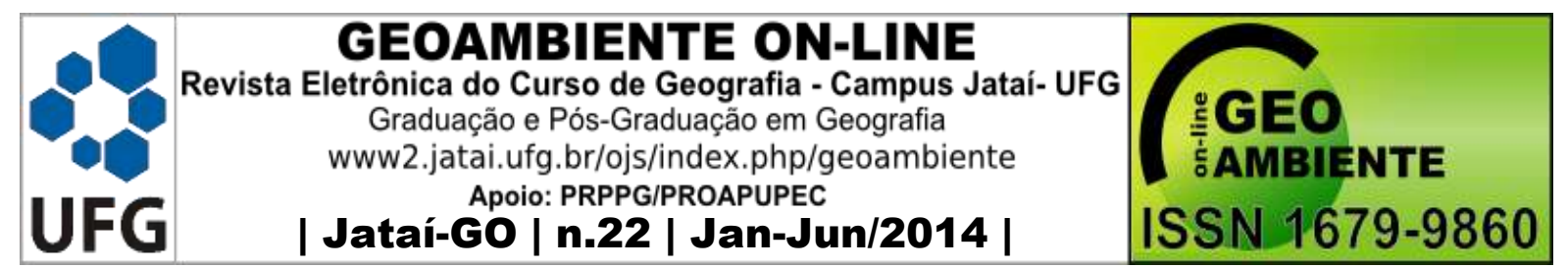

The main objective of this work consists in the analysis of the interaction of land use and limnological variables in the Watershed of Alberti creek, situated in the municipality of São João do Polêsine / RS. In order to achieve this objective, the main channel was divided in five sections based on the geomorphology and access to the area, so the water collection points in each section could be defined. The classification of land use was obtained from the image sensor ETM+ of LANDSAT 7 satellite. To identify the land use, the following sections were defined: forest, field, agriculture, water and urban area. The limnological variables used were: electrical conductivity, $\mathrm{pH}$, water temperature and total of solids in suspension. The analysis of these variables showed that different land uses create different environments throughout the course of the creek, thus altering in some way all limnological variables. The variables $\mathrm{pH}$ and total of solids in suspension were the most dependent on land use. The most altered values for those variables occured in the sample points near the urban area of São João do Polêsine, which is a consequence of anthropical interventions.

Keywords: Limnology, Remote Sensing, Watershed

\section{Resumen}

INFLUENCIA DEL USO DE LA TIERRA EN VARIABLES LIMNOLÓGICAS EN LA MICROCUENCA HIDROGRÁFICA DEL ARROYO ALBERTI - SÃO JOÃO DO

\section{POLÊSINE/RS}

El objetivo general del trabajo es analizar la interacción del uso de la tierra con variables limnológicas en la microcuenca del arroyo Alberti, localizada en el municipio São João do Polêsine / RS. Para alcanzar este objetivo, el cauce del río principal fue dividido en cinco secciones basado en la geomorfología y el acceso al lugar, de manera de definir los puntos de colecta de agua en cada sección. La clasificación de uso de la tierra se obtuvo a partir de una imagen del sensor ETM+ del satélite LANDSAT 7. Para la identificación del uso de la tierra se definieron las siguientes clases: bosque, campo, agricultura, agua y área urbana. Las variables limnológicas consideradas fueron: conductividad eléctrica, $\mathrm{pH}$, temperatura del agua y total de sólidos en suspensión. El análisis de estas variables permitió identificar que los distintos usos de la tierra proporcionan ambientes diferenciados a lo largo del arroyo y esto se refleja en todas las variables limnológicas. Las variables que resultaron ser más dependientes del uso de la tierra fueron $\mathrm{pH}$ y total de sólidos en suspensión. Los valores más elevados de 


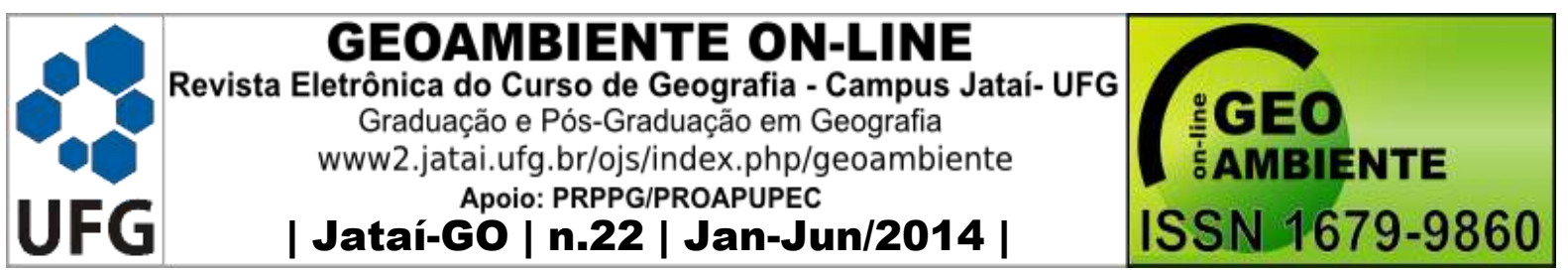

estas variables se constataron en los puntos muestrales localizados próximos al núcleo urbano de São João do Polêsine, reflejo de las intervenciones antrópicas.

Palabras clave: Limnologia, Percepción Remota, Microcuenca Hidrográfica

\section{Introdução}

O movimento da água no planeta está ligado ao Ciclo Hidrológico, que é o movimento perpétuo da água na biosfera, e os fenômenos da evaporação e precipitação são os principais elementos responsáveis pela contínua circulação da água pela Terra (ESTEVES; SILVA; ALBERTONI, 2011). Segundo Tundisi (2005, p. 5) "O ciclo é o modelo pelo qual se representam a interdependência e o movimento contínuo da água nas fases sólidas, líquida e gasosa". E está em contínuo movimento cíclico entre as reservas, sendo a fase líquida a mais importante. Para Silveira (2012, p. 35), “O ciclo hidrológico é o fenômeno global de circulação fechado da água entre a superfície terrestre e a atmosfera, impulsionando fundamentalmente pela energia solar associada à gravidade e à rotação terrestre".

Um problema que tem gerado grandes discussões em todo o mundo está relacionado à escassez de água, que por sinal vem se agravado muito nas ultimas décadas. A Organização das Nações Unidas - ONU (1991) - elegeu as questões relacionadas à água como o grande desafio a ser resolvida neste século. Para a sociedade contemporânea a falta de água doce utilizável, é potencialmente um fator limitante maior para a população do que a energia, seja ela qual for (ODUM, 1988).

A escassez de água se reflete negativamente na produção agrícola, no desenvolvimento urbano e industrial e, em particular, no acesso das pessoas a água potável (TUNDISI, 2000). Os esforços empreendidos pelo poder público e pela sociedade, respaldados pela Ciência, deverão encontrar soluções para resolver e equacionar esta grave situação preocupante. Grande parte dos problemas de deterioração dos recursos hídricos estão relacionados com o crescimento e a diversificação das atividades agrícolas, o aumento da urbanização e o aumento e a intensificação das atividades humanas (TUNDISI, 2005).

A maior parte das grandes concentrações urbanas e industriais atualmente localiza-se próxima a grandes mananciais, tornando seus cidadãos dependentes da disponibilidade de água, em quantidade e qualidade. Ela é utilizada para abastecimento doméstico e industrial, além de irrigação e lazer, desta forma, o crescimento populacional é o grande responsável pela crescente necessidade de água, demonstrando que, praticamente todas as atividades 


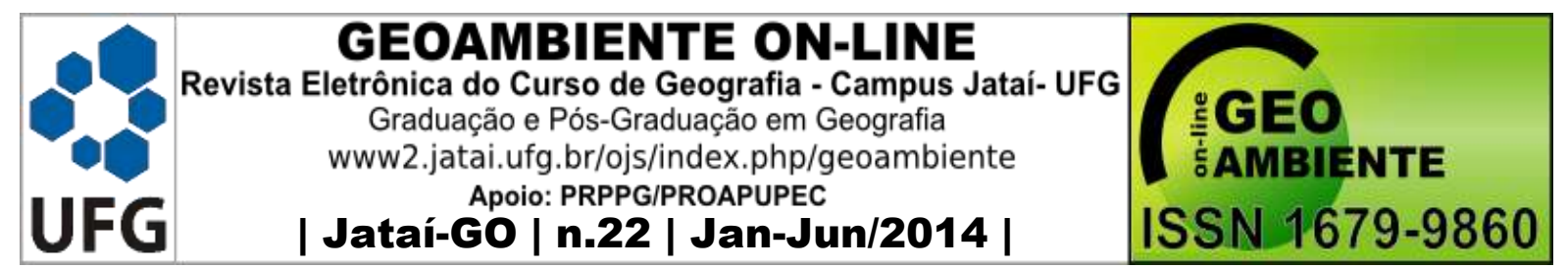

humanas são cada vez mais dependentes da disponibilidade das águas continentais, seja para todas as atividades pessoais, profissionais e em coletividade, essa dependência é ainda mais evidente nas regiões altamente industrializadas, onde a demanda de água per capita/habitante tem se tornado cada vez maior (ESTEVES; MENEZES, 2011).

Um fenômeno de grande relevância atualmente é o crescimento dos índices de urbanização. $\mathrm{O}$ aumento da malha urbana, em muitos casos à margem da legislação de uso do solo e associada à especulação imobiliária, resulta na ocupação de áreas sem infraestrutura sanitária inadequada, gerando como consequência a degradação da qualidade das águas naturais. Assim sendo, pode-se afirmar que uma das principais causas da degradação das águas no espaço urbano é o lançamento de efluentes domésticos sem o tratamento apropriado, ricos em nutrientes e matéria orgânica (MAROTTA; SANTOS; ENRICH-PRAST, 2008).

O manejo inadequado da bacia hidrográfica sem práticas de conservação do solo, como contenção de enxurradas, produz a perda de nutrientes do solo, que, transportados pela água das chuvas são depositados no leito dos rios. Nutrientes produzidos pela indústria como nitrogênio, fósforo, potássio, que são aplicados em grandes quantidades na agricultura, quando introduzidos em excesso aos ambientes aquáticos fornecem sustento extra ao fitoplâncton e macrófitas aquáticas, podendo ocasionar a eutrofização desses ambientes.

No complexo equilíbrio dos ambientes aquáticos como nos córregos, arroios e rios as características limnológicas são influenciadas negativamente por diversos fatores, como por exemplo, a descarga de efluentes urbanos ou industriais sem tratamento e o uso do solo de forma inapropriada em áreas adjacentes, demonstrando uma relação estreita entre estas variáveis e suas condições ou aspectos biológicos, químicos, físicos, geológicos, meteorológicos ou ecológicos (BARIANI, 2012).

Em estudo de duas bacias de drenagem na região centro-sul do estado do Paraná e analisando comparativamente parâmetros limnológicos foi verificado entre os ambientes lóticos, similaridade numérica entre todos os parâmetros avaliados. Os autores consideram à vista disso, que a proximidade geográfica, além de fatores como o clima, a geologia e o regime hidrológico influenciam nas características limnológicas das áreas em estudo, ressaltando, assim, a importância de fatores regionais (KRUPEK; BRANCO; PERES, 2012).

O tema central deste artigo consiste em um estudo que identifica relações entre ecossistemas terrestres e aquáticos a partir de dados geográficos e limnológicos no arroio Alberti, localizados no município de São João do Polêsine/RS. 


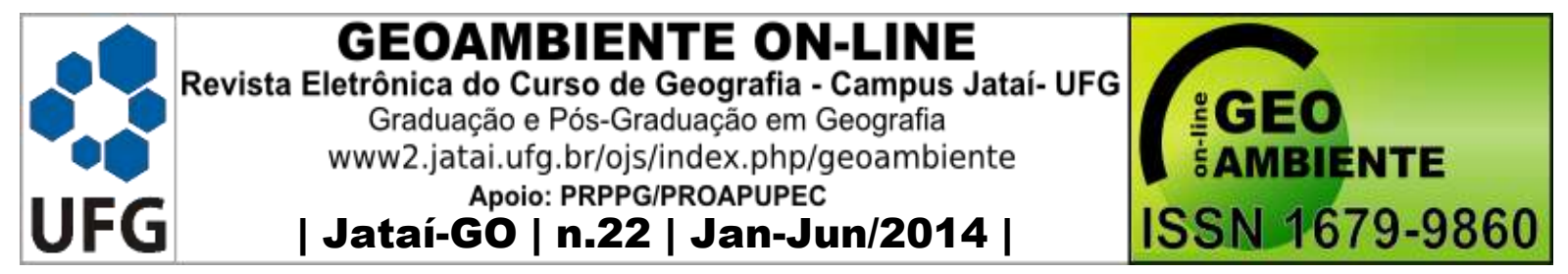

Para que o objetivo geral fosse atingido os seguintes objetivos específicos foram definidos:

- Identificar a relação dos dados limnológicos com as seções dos cursos d'água devido à presença da cidade de São João do Polêsine e áreas rurais junto ao arroio Alberti;

- Analisar as influências dos diferentes tipos de uso da Terra sobre variáveis nas águas do arroio Alberti;

- Relacionar as alterações em variáveis limnológicas com diferentes fases da produção agrícola (fase de preparo da terra e fase de desenvolvimento das culturas agrícolas).

\section{Caracterização Geral da Área}

As estruturas que formam o relevo do Rio Grande do Sul são compostas de litologias e altimetrias variadas, que oscilam desde o nível do mar, na Planície Litorânea até ultrapassar os 1.000 metros no Planalto Basáltico no Nordeste do Estado. Segundo Müller Filho (1970, p. 9), "Nos traços mais gerais, a Geologia do Sul do Brasil e, em particular a do Rio Grande do Sul é simples: um escudo cristalino, separado de um planalto de efusivas básicas, por uma depressão denudacional de rochas sedimentares, e com uma estreita franja litorânea de sedimentos recentes".

A geomorfologia da área de estudo apresenta um espaço morfoestrutural, pertencente aos seguintes compartimentos: Rebordo do Planalto Meridional Brasileiro, conhecido como Serra Geral, composto por rochas sedimentares e vulcânicas; Depressão Central ou Periférica, que apresenta uma configuração de coxilhas e planícies aluviais e os sedimentos Quaternários recentes (KLAMT, 1997).

O que caracteriza a Depressão Central é a existência de grandes extensões de planície aluviais e coxilhas sedimentares com declividade média. Os solos são de origem diferentes e om limitações moderadas a muito forte quanto à produção agrícola (IENSEN, 2009).

Os aluviões caracterizam-se por sedimentos do Pleistoceno e Holoceno depositados pelos rios no seu leito maior e material provindos dos compartimentos mais elevados. Os solos destas áreas são derivados de sedimento aluvionares de duas formações: i) aluviões compostos por (areias, argilas e cascalhos fluviais) e terraços fluviais, constituídos por (conglomerados, arenitos médios argilosos e siltitos arenosos fluviais) (KURTZ, 2002). 


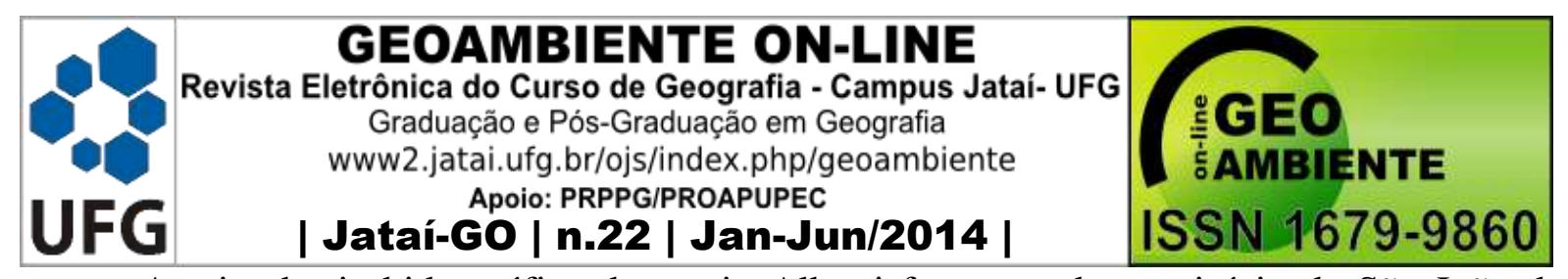

A microbacia hidrográfica do arroio Alberti faz parte do município de São João do Polêsine que está localizado na região central do Rio Grande do Sul, na transição entre o Rebordo do Planalto Meridional e a Depressão Central ou Periférica.

A área de estudo foi delimitada utilizando-se como base cartográfica a Carta Topográfica de Faxinal do Soturno, folha (SH.22-V-C-V-I), escala 1:50.000, produzida pela Diretoria de Serviço Geográfico do Exército e publicada em 1980 (DSG, 1980). Tendo por base o sistema de drenagem do Arroio Alberti e pelo divisor de águas, com base nas curvas de nível, delimitou-se a sua bacia hidrográfica, totalizando uma área de 7,6 km².

Com a delimitação da microbacia, a área de estudo ficou enquadrada entre as

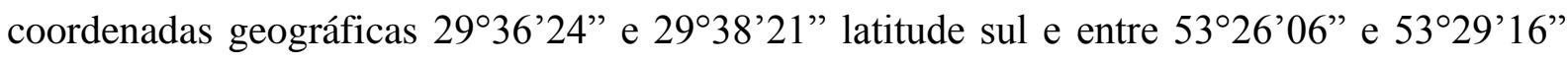
longitude oeste (Figura 1).

\section{Metodologia}

Identificou-se em trabalho de campo, os diferentes tipos de uso da terra que melhor representam a realidade da área estudada e também definiu-se os pontos da coleta de água. Foram alocados no arroio Alberti 5 pontos amostrais, numerados e nomeados sequencialmente. São estes os pontos: 1/Alto curso; 2/Ponte; 3/Início Canalização; 4/Final Canalização e 5/Foz.

A amostragem da água foi realizada em duas etapas distintas, observando-se a fase da produção agrícola. A primeira etapa foi realizada no período de preparo do solo e plantio, foram realizadas 4 coletas com intervalo de duas semanas entre elas, nos dias 14/10/2002, 28/10/2002, 11/11/2002 e 25/11/2002. A segunda etapa foi realizada na fase de florescimento fenológico das culturas agrícolas, correspondendo a $5^{\text {a }}$ e $6^{\text {a }}$ coletas, também com intervalo entre as coletas de duas semanas, cumprida nos dias 22/01/2003 e 05/02/2003; ou seja, após 57 dias de intervalo da etapa anterior. Todas as coletas foram realizadas as segundas-feiras iniciando pela manhã e prolongando-se até a primeira hora da tarde. Portanto, foram realizadas seis coletas de água. Os dados referem-se a algumas características da água em ambiente lótico, as informações extraídas diz respeito a duas condições distintas a primeira, atribuída a coletas de variáveis a campo, tais como: condutividade elétrica (CE), pH, temperatura da água $\left(\mathrm{T}^{\circ} \mathrm{C}\right)$, e a segunda condição em laboratório, para determinação do Total de Sólidos em Suspensão (TSS). 


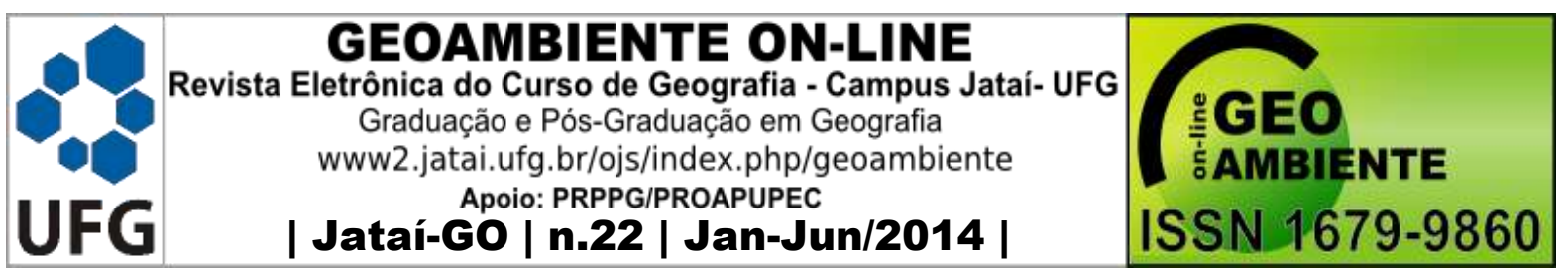

Figura 1: Localização dos pontos de coleta na microbacia hidrográfica do arroio Alberti-RS.

\section{LOCALIZAÇÃO DOS PONTOS DE COLETA NA MICROBACIA DO ARROIO ALBERTI - RS}

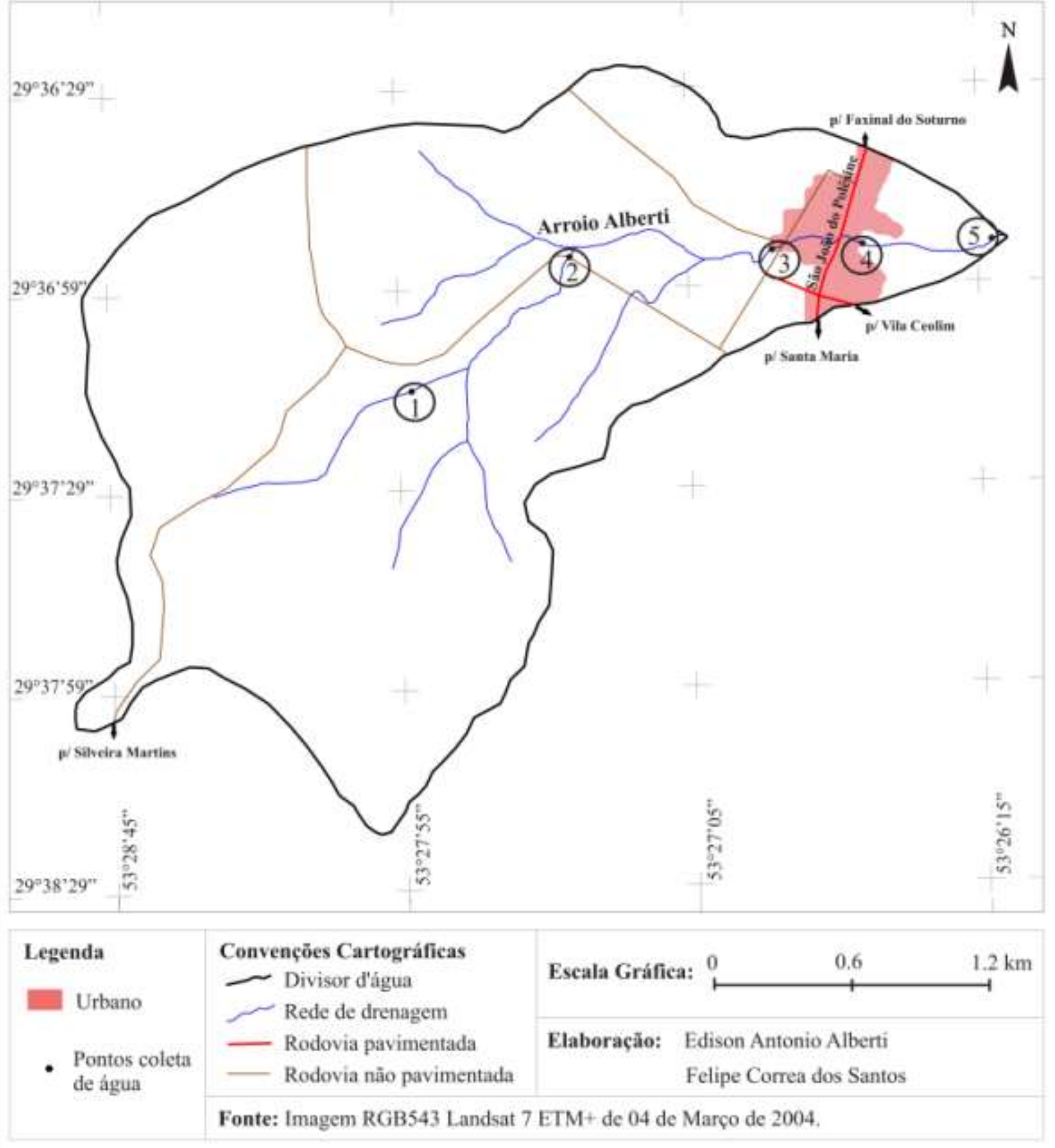

As coletas de amostras de água obedeceram a determinações técnicas, sendo que para isso foram utilizados recipientes plásticos próprios para este fim, devidamente identificados e esterilizados, conforme normas da Companhia de Tecnologia de Saneamento Ambiental CETESB, a partir da metodologia definida em Agudo et al. (1987). Para a determinação dos 


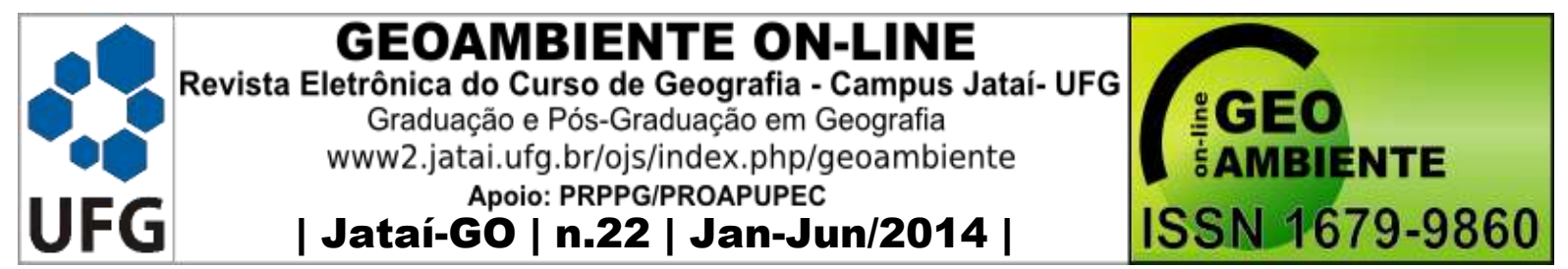

valores de TSS em laboratório foi realizada com método de filtragem da água conforme apresentado em APHA (2005).

Para a determinação do TSS foi utilizado filtro de celulose constituído por membranas $H A$ em Ester de Celulose com poros de 0,45 $\mu \mathrm{m}$, diâmetro de $47 \mathrm{~mm}$, branco, quadriculado, estéril, fabricado pela Millipore.

O TSS índica a presença de substâncias particuladas suspensas na água, sejam elas, orgânicas, inorgânicas, microrganismos e fitoplâncton. Isso ocorre devido principalmente a duas propriedades físicas da água: o peso específico e a viscosidade. O elevado peso específico da água, possibilita a existência da flora e fauna, bem como de outros materiais particulados em suspensão, como por exemplo, os síltes e as argilas. O peso específico está relacionado a densidade da água, ou seja, a água no estado líquido possui maior densidade do que no estado sólido (gelo), nesta situação lagos e rios em regiões frias o gelo flutua na superfície e possibilita a existência de organismos aquáticos logo a baixo do gelo (ESTEVES; SANTOS, 2011). Já a viscosidade é a resistência que a água oferece ao deslocamento de todos os organismos e elementos presentes na água, sejam eles microscópicos e/ou macroscópicos.

Na classificação do uso da terra foi utilizada a imagem do satélite LANDSAT 7, sensor ETM+, órbita ponto 222/81, (passagem do satélite dia 04/03/2004). As classes criadas foram floresta, campo, água, área urbana e agricultura, e identificadas na imagem a partir da interpretação visual em tela com o uso de polígonos que delimitaram cada classe. Para análise da imagem de satélite utilizou-se a composição colorida das bandas 5, 4, 3 em RGB, com associação das cores vermelho, verde e azul, respectivamente. Na identificação da classe floresta foi delimitado os estratos arbóreos, tanto de floresta nativa como da floresta exótica, para tanto foi observado na imagem de satélite algumas características específicas desta classe como, por exemplo, a cor na imagem de satélite, a forma do polígono e a textura, para as outras classes foi adotado este mesmo procedimento. Na classe agricultura a classificação foi identificar as áreas com solo exposto preparadas para o plantio, bem como, as áreas onde as culturas já haviam sido plantadas e estavam em estágio mais avançado de desenvolvimento.

\section{Resultados}

\subsection{Uso da Terra na microbacia do arroio Alberti}

Os tipos de usos da terra da microbacia são destacados por cinco classes temáticas. $\mathrm{Na}$ Tabela 1 são apresentados os resultados da classificação do uso da terra na microbacia do 


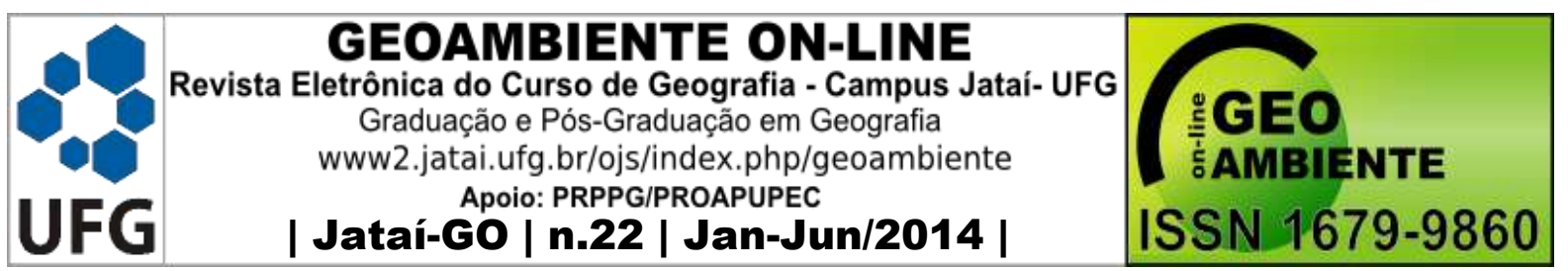

arroio Alberti, com seus respectivos percentuais, bem como os critérios: cor na imagem de satélite, forma e textura adotada para cada classe na interpretação visual da imagem de satélite.

Tabela 1: Quantificação do uso da terra na microbacia do arroio Alberti.

\begin{tabular}{l|c|c|c|c|c}
\hline \multicolumn{1}{c|}{ Classe } & $\begin{array}{c}\text { Cor na imagem } \\
\text { de satélite }\end{array}$ & Forma & Textura & Área (ha) & \% sobre o total \\
\hline Floresta & Verde & Irregular & Rugosa & 350,00 & 46,05 \\
\hline Água & Azul & Irregular & Lisa & 1,00 & 0,13 \\
\hline Campo & Amarelo & Irregular & Lisa & 310,00 & 40,79 \\
\hline Agricultura & Marrom & Irregular & Lisa & 69,00 & 9,08 \\
\hline $\begin{array}{l}\text { Área } \\
\text { urbana }\end{array}$ & Magenta & Regular & Mosqueada & 30,00 & 3,95 \\
\hline Total & - & - & - & 760,00 & 100,00 \\
\hline
\end{tabular}

Com a utilização desta técnica de geoprocessamento foi possível individualizar e mapear cinco classes de uso da terra que são as de maior relevância na microbacia em estudo (Figura 2).

As áreas agrícolas estão bem dispersas sobre a microbacia, possui aproximadamente 69 ha, o que representa 9,08 \% do total da área. Estão localizadas principalmente na área mais central da microbacia e em áreas com declividade mais suave, propícia à mecanização agrícola. Nestas áreas planas de várzeas o arroz irrigado é a cultura agrícola predominante, além deste cereal são cultivados a soja e o milho em menor escala.

Os campos somam 40,79\% sobre o total da área distribuído em toda a microbacia estudada, exceto no extremo oeste onde predomina a floresta. Ocupam as áreas de transição entre o Rebordo do Planalto e a Depressão Central. Estes, são utilizados principalmente para a criação do rebanho bovino e de forma extensiva.

A classe floresta possui 46,05 \% da área da microbacia e ocupa as áreas mais íngremes principalmente no extremo oeste da microbacia e em pequenas áreas isoladas. Sendo esparsas, podem pertencer à espécie exótica, principalmente o Eucalyptus $s p$. Estas áreas são importantes para manter o equilíbrio natural, principalmente em áreas íngremes onde a vegetação de porte arbórea retém o excesso de água precipitada diminuindo sensivelmente a erosão.

A classe água, representada pelos açudes, ocupa aproximadamente $0,13 \%$ do total da área, são utilizados na irrigação do arroz, a cultura predominante no município, e também 


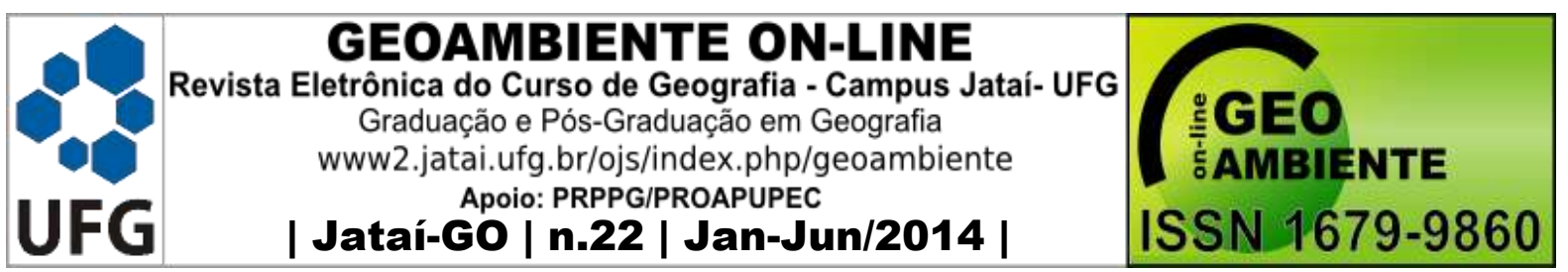

como reservatório de água para dessedentação de animais. Estes açudes são de pequena dimensão e estão localizados no centro da microbacia junto às áreas agrícolas.

Figura 2: Mapa de uso da Terra da microbacia do arroio Alberti/RS.

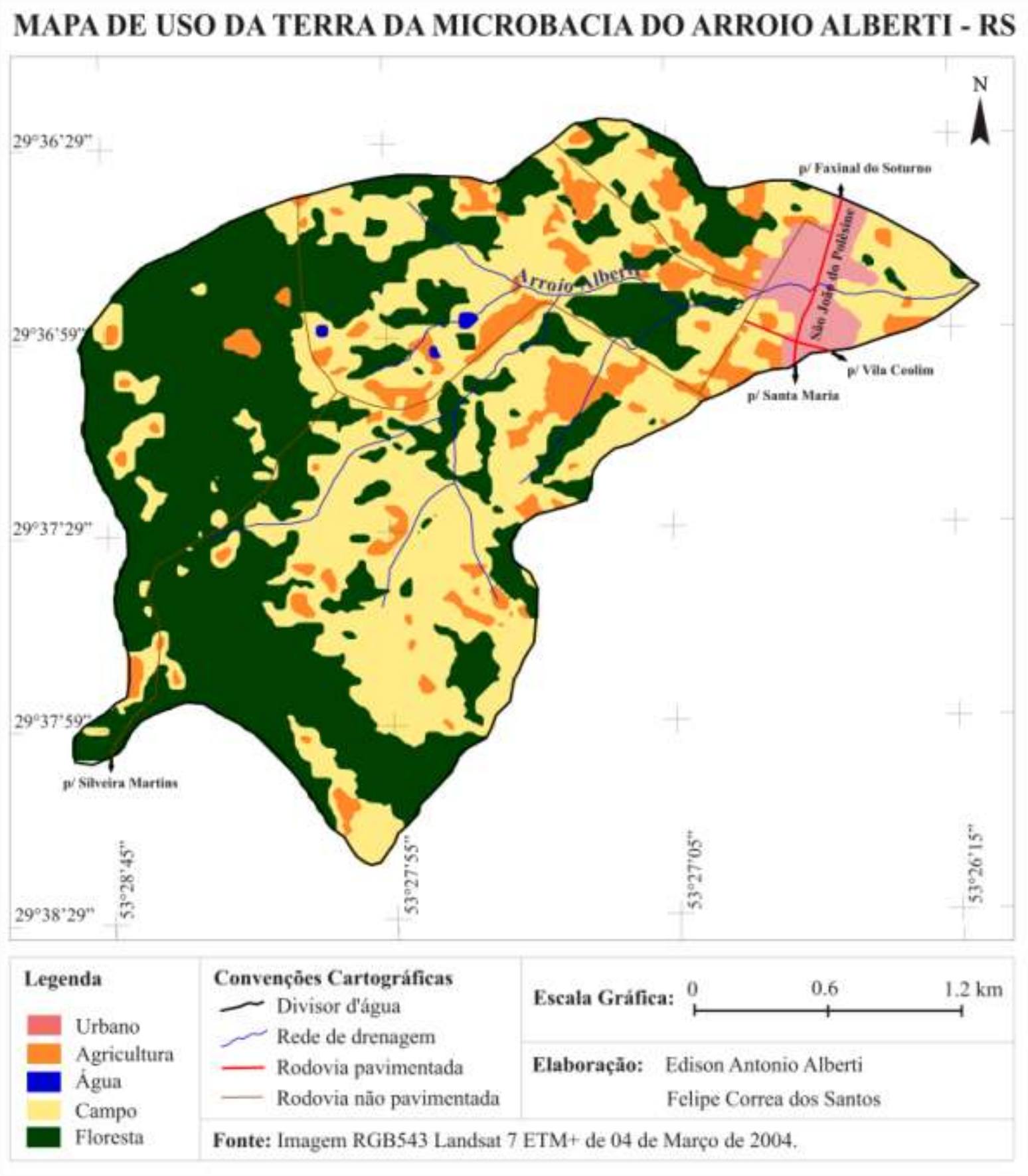

A área urbana ocupa aproximadamente 3,95\% da área, só é maior que a classe temática água. A maior parte das águas residuárias do perímetro urbano e do escoamento pluvial é direcionada ao arroio Alberti. Esta classe ocupa uma área pequena se comparada 


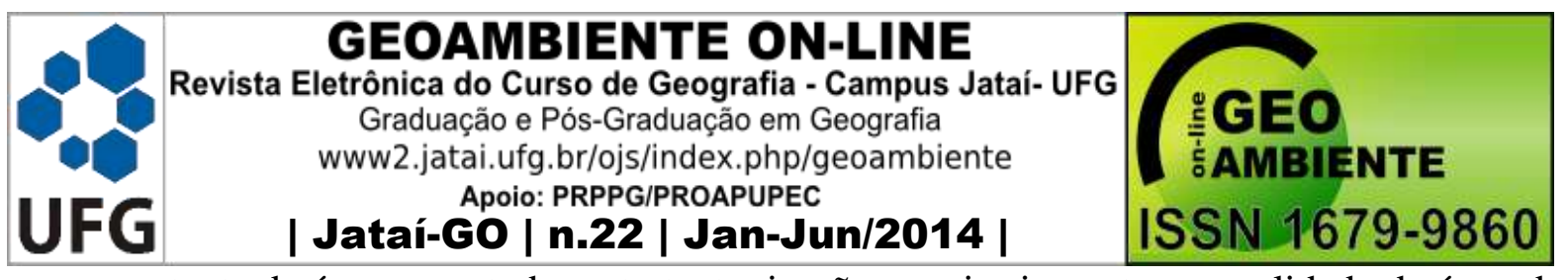

com o restante da área em estudo, entretanto, impõe o maior impacto na qualidade da água do manancial, como veremos mais adiante.

As áreas agrícolas, durante o ano de produção, passam por modificações importantes após a colheita. $\mathrm{Na}$ época da entressafra permanecem em pousio, principalmente as áreas cultivadas com arroz, por serem áreas de várzea, são muito úmidas, não se prestando para culturas de inverno. Em muitos casos, após a colheita, a palha do arroz é incorporada ao solo aguardando a próxima semeadura. Já as áreas mais íngremes cultivadas com soja ou milho é propícia a semeadura de forrageira de inverno para o gado como a aveia e/ou azevem.

\subsection{Variáveis limnológicas}

No Quadro 1 são apresentados os valores dos dados limnológicos referentes às coletas de água realizadas no arroio Alberti, são elas: Condutividade Elétrica (CE); Potencial Hidrogeniônico (pH); Temperatura da água (T); Total de Sólidos em Suspensão (TSS).

Quadro 1: Resultados das variáveis limnológicas.

\begin{tabular}{|c|c|c|c|c|c|c|c|}
\hline & & Unidade & $\begin{array}{l}\text { 1/Alto } \\
\text { Curso }\end{array}$ & 2/Ponte & $\begin{array}{c}\text { 3/Início } \\
\text { Canalização }\end{array}$ & $\begin{array}{c}\text { 4/Fim } \\
\text { Canalização }\end{array}$ & $5 / \mathrm{Foz}$ \\
\hline \multirow{4}{*}{ 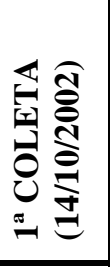 } & $\mathbf{C E}$ & $\mu \mathrm{S} / \mathrm{cm}$ & 75,00 & 72,00 & 78,00 & 90,00 & 87,00 \\
\hline & pH & - & 6,90 & 6,96 & 6,88 & 6,95 & 6,73 \\
\hline & $\mathbf{T}$ & ${ }^{\circ} \mathrm{C}$ & 19,00 & 20,40 & 20,80 & 21,00 & 21,20 \\
\hline & $\begin{array}{l}\text { TSS } \\
\text { (Cel.) } \\
\end{array}$ & $\mathrm{mg} / \mathrm{L}$ & 44,40 & 31,20 & 73,60 & 74,70 & 84,60 \\
\hline \multirow{4}{*}{ 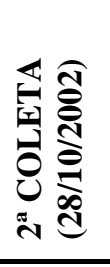 } & $\mathbf{C E}$ & $\mu \mathrm{S} / \mathrm{cm}$ & 55,30 & 53,70 & 61,90 & 88,40 & 75,80 \\
\hline & pH & - & 6,65 & 6,85 & 6,48 & 7,50 & 7,15 \\
\hline & $\mathbf{T}$ & ${ }^{\circ} \mathrm{C}$ & 18,70 & 19,70 & 20,60 & 21,20 & 22,20 \\
\hline & $\begin{array}{l}\text { TSS } \\
\text { (Cel.) } \\
\end{array}$ & $\mathrm{mg} / \mathrm{L}$ & 31,20 & 12,20 & 18,40 & 22,10 & 27,60 \\
\hline \multirow{4}{*}{ 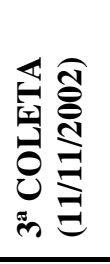 } & $\mathbf{C E}$ & $\mu \mathrm{S} / \mathrm{cm}$ & 45,10 & 44,10 & 48,90 & 71,50 & 62,50 \\
\hline & pH & - & 6,55 & 6,08 & 6,50 & 6,95 & 6,95 \\
\hline & $\mathbf{T}$ & ${ }^{\circ} \mathrm{C}$ & 16,80 & 16,70 & 17,20 & 17,60 & 17,90 \\
\hline & $\begin{array}{l}\text { TSS } \\
\text { (Cel.) } \\
\end{array}$ & $\mathrm{mg} / \mathrm{L}$ & 37,20 & 13,80 & 219,40 & 175,80 & 107,40 \\
\hline \multirow{4}{*}{ 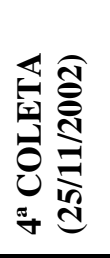 } & CE & $\mu \mathrm{S} / \mathrm{cm}$ & 60,70 & 61,20 & 70,00 & 129,30 & 89,30 \\
\hline & pH & - & 6,85 & 6,75 & 6,93 & 7,16 & 6,72 \\
\hline & $\mathbf{T}$ & ${ }^{\circ} \mathrm{C}$ & 20,20 & 21,80 & 23,10 & 23,30 & 23,30 \\
\hline & $\begin{array}{l}\text { TSS } \\
\text { (Cel.) } \\
\end{array}$ & $\mathrm{mg} / \mathrm{L}$ & 52,00 & 35,40 & 36,40 & 40,60 & 38,60 \\
\hline $\ln N$ & $\mathbf{C E}$ & $\mu \mathrm{S} / \mathrm{cm}$ & 71,30 & 76,00 & 135,00 & 331,00 & 144,10 \\
\hline
\end{tabular}




\begin{tabular}{|c|c|c|c|c|c|c|c|}
\hline 1 & Revist & $\begin{array}{l}\text { E0AI } \\
\text { nica do } \\
\text { raduaçã } \\
\text { v2.jatai. } \\
\text { aí-GC }\end{array}$ & $\begin{array}{l}\text { IEN" } \\
\text { oo de G } \\
\text { ós-Grad } \\
\text { or/ojs/ir } \\
\text { RPPG/P } \\
\text { |.22 }\end{array}$ & $\begin{array}{l}\text { ON- } \\
\text { afia-C } \\
\text { oem Ge } \\
\text { php/ge } \\
\text { UPEC } \\
\text { n-Ju }\end{array}$ & $\begin{array}{l}\text { lataí- UFG } \\
\text { te }\end{array}$ & $\begin{array}{l}\text { ¿ GEO } \\
\text { ISAMBIE } 16 \\
\text { ISSN }\end{array}$ & $\begin{array}{l}\text { TE } \\
-9860\end{array}$ \\
\hline & pH & - & 6,90 & 7,10 & 7,08 & 7,28 & 6,88 \\
\hline & $\mathbf{T}$ & ${ }^{\circ} \mathrm{C}$ & 21,70 & 23,90 & 25,80 & 27,20 & 24,70 \\
\hline & $\begin{array}{l}\text { TSS } \\
\text { (Cel.) }\end{array}$ & $\mathrm{mg} / \mathrm{L}$ & 41,20 & 7,00 & 17,00 & 20,60 & 22,20 \\
\hline \multirow{4}{*}{ 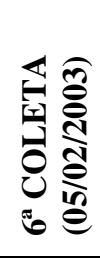 } & $\mathbf{C E}$ & $\mu \mathrm{S} / \mathrm{cm}$ & 75,10 & 83,00 & 127,50 & 189,00 & 184,80 \\
\hline & pH & - & 6,89 & 6,28 & 7,11 & 7,13 & 7,19 \\
\hline & $\mathbf{T}$ & ${ }^{\circ} \mathrm{C}$ & 23,60 & 25,70 & 28,10 & 28,90 & 28,10 \\
\hline & $\begin{array}{l}\text { TSS } \\
\text { (Cel.) }\end{array}$ & $\mathrm{mg} / \mathrm{L}$ & 30,00 & 4,20 & 6,20 & 12,80 & 8,80 \\
\hline
\end{tabular}

\subsubsection{Condutividade Elétrica (CE)}

O conceito de Condutividade Elétrica indica que é a capacidade de uma água conduzir a corrente elétrica. Ela depende da concentração de sais dissolvidos e da temperatura. A faixa de variação nas 6 coletas ficou entre 44,1 até 331,0 $\mu \mathrm{S} / \mathrm{cm}$. Os altos valores de condutividade, principalmente na $5^{\mathrm{a}}$ e $6^{\mathrm{a}}$ coleta nos pontos 3 a 5 podem estar relacionados a atividade antrópica junto aos pontos de coleta ou seja, transferência de materiais entre o sistema terrestre e o aquático, neste caso o lançamento de esgoto in natura no arroio.

A Figura 3 representa graficamente os resultados dos valores da condutividade elétrica no arroio Alberti. A condutividade elétrica no arroio Alberti, aumentam progressivamente a partir do ponto $1 \mathrm{com}$ pico em todas as coletas no ponto 4. Este fato está relacionado com o lançamento de esgoto urbano a montante daquela estação amostral. A partir deste, os valores da condutividade elétrica voltam a decrescer à medida que há um aumento da distância do ponto amostral, voltando à estabilidade no sistema. Esta condição mostra uma capacidade de autodepuração deste manancial, em relação aos sais dissolvidos.

Figura 3: Variação da Condutividade Elétrica no arroio Alberti.

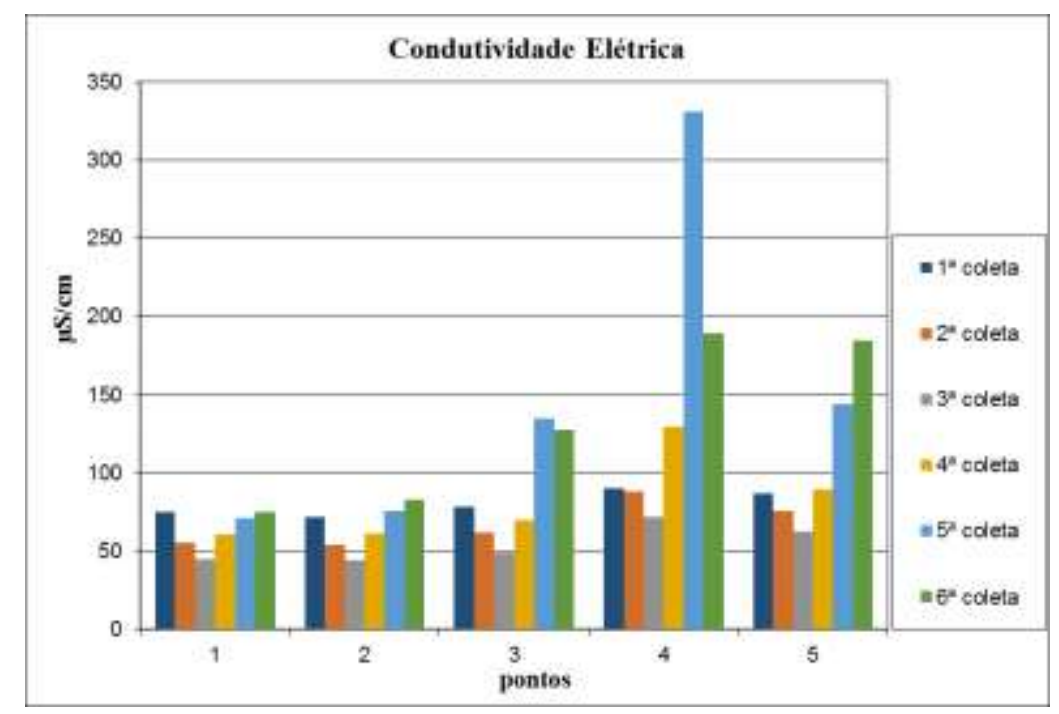




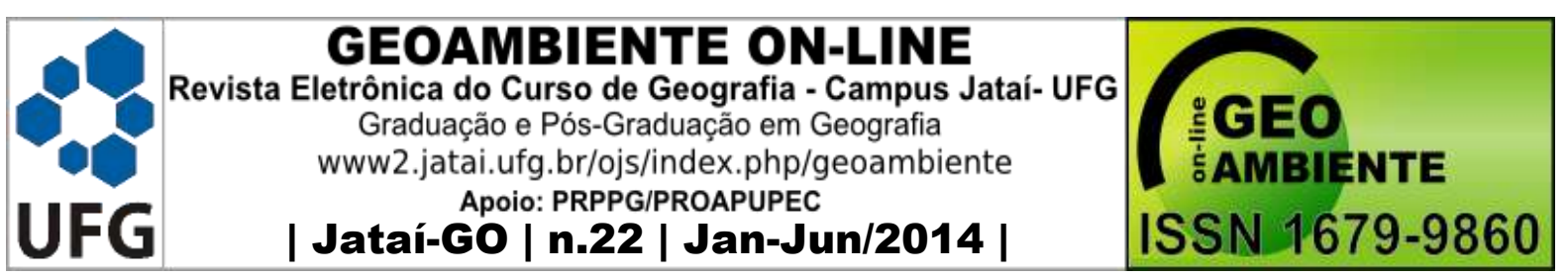

Outra observação importante diz respeito a $3^{\mathrm{a}}$ coleta, pois os valores desta variável são inferiores a todas as outras coletas, este fato está relacionado com o volume de chuva precipitado $(47 \mathrm{~mm}$ ) nas 24 horas que antecederam a coleta, aumentando o volume de água e consequentemente diluindo a concentração da composição iônica da água.

\subsubsection{Potencial Hidrogeniônico (pH)}

$\mathrm{O}$ pH da água apresenta uma variação acentuada de seus valores em todas as coletas (Figura 4), oscilando entre 6,08 a 7,50, mesmo assim, encontra-se dentro dos limites recomendáveis para a manutenção da vida aquática em equilíbrio, bem como dentro dos limites estabelecidos pela Resolução CONAMA N²0/86, que estabelece a faixa de 6,0 a 9,0 como limite tolerável para as águas das classes 1 a 4 - águas doces.

Figura 4: Variação do pH no arroio Alberti.

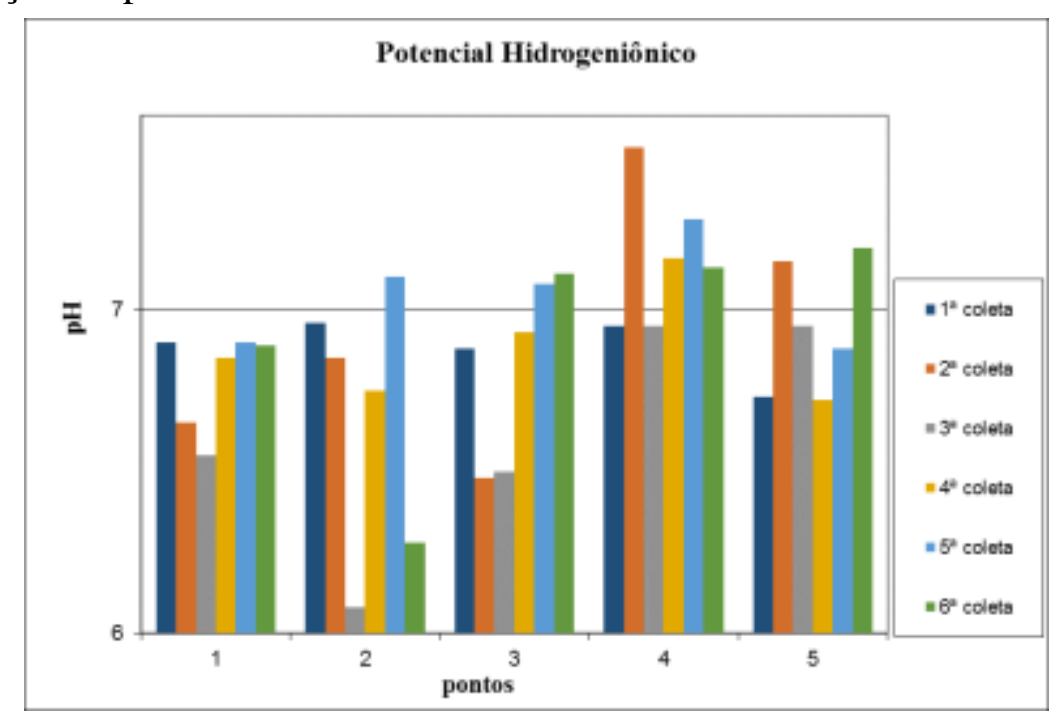

Este indicador fornece a condição da água, se a mesma é ácida (pH inferior a 7), se é neutra ( $\mathrm{pH}$ igual a 7) ou se é alcalina ( $\mathrm{pH}$ maior do que 7), dependendo da origem e das características da água, sendo que esta variável pode ser alterada quando da introdução de resíduos, como foi verificado nos valores obtidos com as amostras de água retiradas do arroio.

$\mathrm{O} \mathrm{pH}$ no ponto 1 apresenta certa homogeneidade nos valores ( $\mathrm{pH}$ ácido a levemente ácido), devido possivelmente ao ambiente natural relativamente preservado, à medida que o arroio segue seu curso, estes valores vão se alterando mais intensamente, isto devido à interferência exercida pelas atividades agrícolas até o ponto 3. No ponto $4 \mathrm{o} \mathrm{pH}$ apresenta leve 


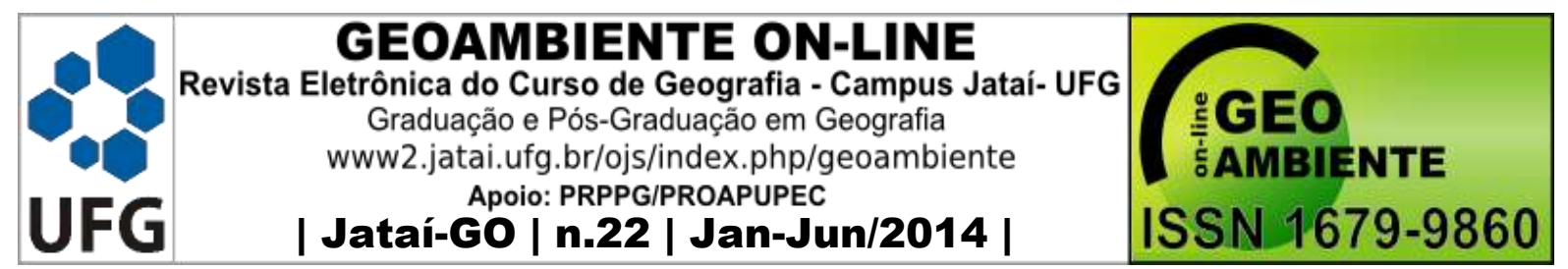

tendência de aumento do grau de alcalinidade, influenciado pelos efluentes da cidade. A partir daquele ponto, volta a dominar a atividade agropecuária, percebe-se que $\mathrm{o} \mathrm{pH}$ no ponto 5 tende a voltar aos valores de $\mathrm{pH}$ neutro, presumindo-se a autodepuração deste manancial, mas ainda sob influência do esgoto.

$\mathrm{O}$ pH da água do arroio Alberti verifica-se em suas amostragens uma tendência de água ácida ( $\mathrm{pH}$ inferior a 7) principalmente nos pontos 1 a 3 . No ponto $4 \mathrm{o} \mathrm{pH}$ tende a alcalino, quase neutro, esta tendência se verifica quando da proximidade da áreas urbana, esta elevação do pH possivelmente se deve ao lançamento de esgoto urbano no arroio alterando significativamente o valor do $\mathrm{pH}$. No ponto 5 a tendência é de diminuição do índice de $\mathrm{pH}$ à medida que se afasta do local de lançamento de esgoto urbano voltando à estabilidade do sistema.

\subsubsection{Temperatura $(T)$}

A temperatura da água é um parâmetro ambiental de grande importância devido sua influência sobre os seres vivos aquáticos. Uma série de condicionantes intervém na temperatura superficial da água, tais como: estação do ano, circulação do ar, hora do dia, cobertura de nuvens, profundidade do corpo d'água, vazão, latitude e altitude.

A Figura 5, mostra as variações da temperatura na água do arroio Alberti. Nas 6 coletas a variação oscilou de $16,7^{\circ} \mathrm{C}$ de mínima a $28,9^{\circ} \mathrm{C}$ de máxima. A $3^{\text {a }}$ coleta apresentam as menores temperaturas em todos os pontos, as temperaturas mais baixas pode ser atribuída por causa da mudança do tempo, pois choveu no dia anterior ao campo. A partir desta data as temperaturas aumentam conforme passam as estações do ano, estando diretamente influenciadas pelas condições climáticas e também aumentam conforme vão passando as horas do dia.

Analisando-se a variação da temperatura tendo em vista os pontos das coletas verificase a tendência da maior temperatura, se concentrar em um ponto específico, no arroio Alberti, esta tendência concentra-se no ponto 4, que pode estar relacionada com o lançamento de esgoto à montante aumentando a concentração de material particulado em suspensão na água contribuindo com a absorção de calor e, também pelo fato desta parte do arroio estar canalizada, o concreto pode ter influenciado mesmo que sensivelmente na temperatura, bem como, a falta da mata ciliar influenciou na temperatura, ou seja a inexistência desta facilita a incidência de radiação solar na água. 


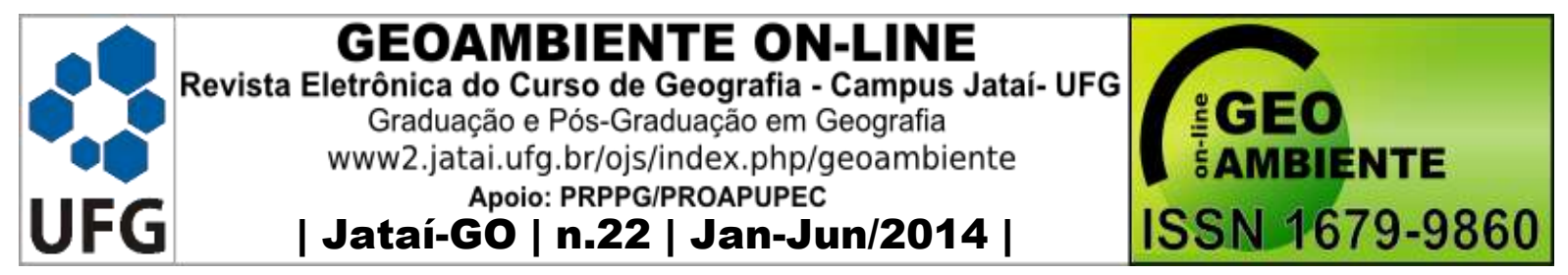

Figura 5: Variação da temperatura da água nos pontos amostrais.

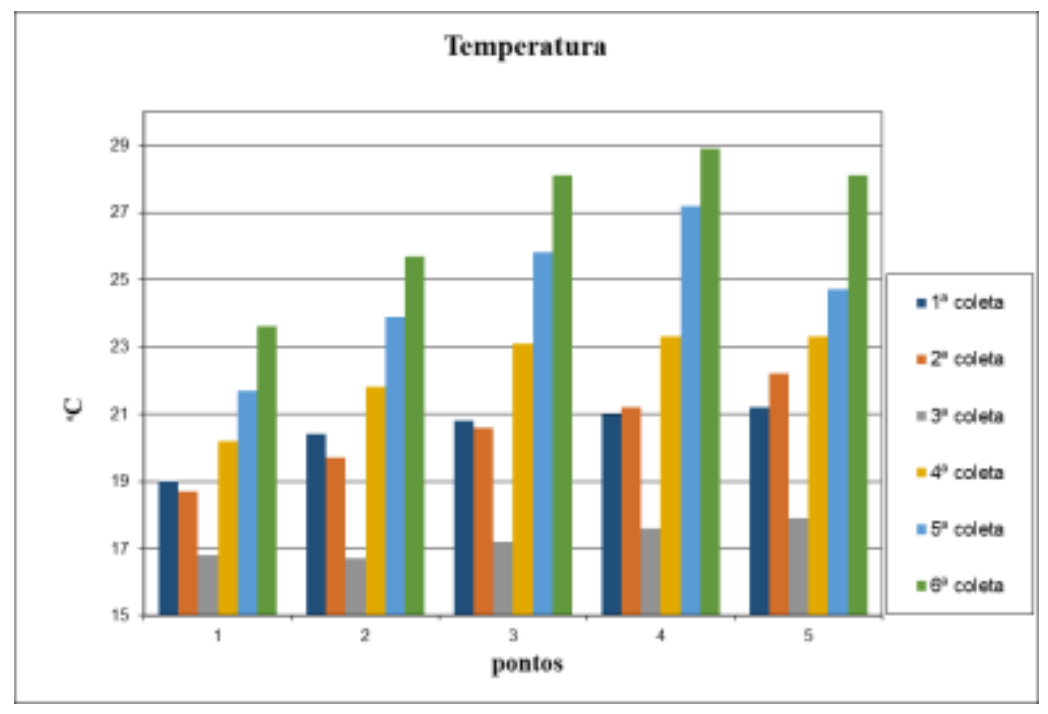

As maiores temperaturas ocorreram na $5^{\mathrm{a}}$ e $6^{\mathrm{a}}$ coletas, isto se deve possivelmente ao período de coleta, ou seja, fim de janeiro e início de fevereiro, coincidindo com o período mais quente do verão.

\subsubsection{Total de Sólidos em Suspensão (TSS)}

Esta variável determina a quantidade de todos elementos que estão em suspensão na água que podem ser interceptados por filtros. A capacidade de retenção de sedimentos de cada tipo de filtro é determinada pelo tamanho dos seus poros. A figura 6 mostra a evolução do TSS na área em estudo.

É importante notar que os valores do TSS nos pontos 1 e 2, tendem a valores mais baixos como mostra o gráfico. Estes pontos estão localizados em área mais escarpada onde predominam as florestas arbórea e campo nativo. Uma característica importante atribuída a essas duas classes é a proteção dada por essas áreas contra as perdas de solo por erosão pluvial, principalmente as áreas com floresta nativa. As áreas de campo, mesmo com a presença de animais, preservam o solo contra a lixiviação e a erosão muito mais do que o solo utilizado para a agricultura.

Os valores do TSS tendem a refletir as respostas do que ocorre na área de captação em função da sua geomorfologia, do tipo de solo, da cobertura vegetal, do clima e, não menos importante, do tipo de ocupação das áreas adjacentes. 


\begin{tabular}{|c|c|c|}
\hline & $\begin{array}{l}\text { GEOAMBIENTE ON-LINE } \\
\text { a Eletrônica do Curso de Geografia - Campus Jataí- UFG } \\
\text { Graduação e Pós-Graduacaão em Geografia } \\
\text { www2.jatai.ufg.br/ojs/index.php/geoambiente } \\
\text { Apoio: PRPPG/PROAPUPEC } \\
\text { | Jataí-GO | n.22 | Jan-Jun/2014 | }\end{array}$ & ISSN $1679-9860$ \\
\hline
\end{tabular}

Figura 6: Variação do TSS no arroio Alberti.

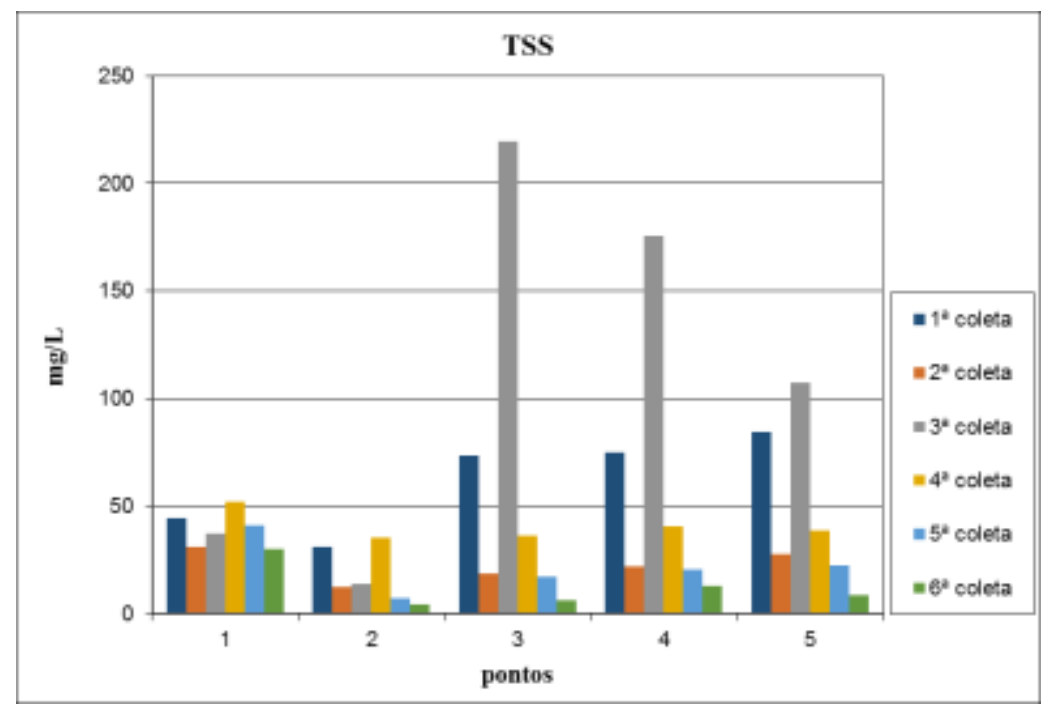

No gráfico acima, verifica-se que no primeiro ponto o TSS apresenta a menor amplitude entre as seis coletas se comparado aos outros pontos. Este, por localizar-se em área mais declivosa a água corrente ganha velocidade, dessa forma contribuindo para o araste de partículas para dentro do leito do arroio e mantendo essa partículas em constante movimento e impede de acumular-se no fundo.

No ponto 2 os valores de TSS são menores pois esta seção do arroio é menos íngreme, diminuindo dessa forma o araste de materiais particulados para o leito, o ambiente do arroio no local da coleta é lêntico, água com fluxo muito calmo, neste caso os sedimentos mais grosseiros e pesados, como as areias, depositam-se no leito devido ao seu maior peso e também à menor agitação da água. A mata-galeria desempenha função importante na preservação das margens dos rios, córregos e arroios, evitando o assoreamento e mantendo o ecossistema em equilíbrio, o que nesta seção do arroio encontrava-se em boas condições se comparado aos outros pontos de coleta este era o ponto que apresentava melhor cobertura vegetal nas margens.

A partir do terceiro ponto o aumento na quantidade de sedimentos em suspenção possivelmente é em virtude da influência da área urbana, e mais intensamente pelas áreas de solo exposto junto ao perímetro urbano os quais podem facilmente ser carreados para o leito do arroio com as chuvas.

Os dados do TSS na $1^{\mathrm{a}}$ e $3^{\mathrm{a}}$ coletas nos pontos 3 , 4 e 5 apresentam valores acima de 50 $\mathrm{mg} / \mathrm{L}$, principalmente na $3^{\mathrm{a}}$ coleta, demonstrando que a medida que o uso da terra se 


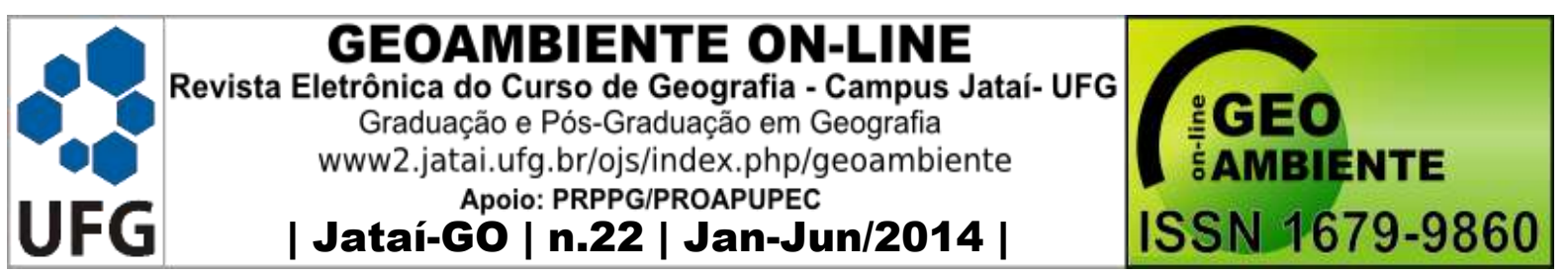

intensifica e diversifica-se, a quantidade de sedimentos na água tende a aumentar. Salienta-se que os pontos 3 e 4 estão alocados em área urbana. Pesa também o fato de que nesses três pontos a mata ciliar foi suprimida. Nessas três seções o uso da terra é intensivo mesclando grandes áreas pavimentadas que é característico das áreas urbanas, agricultura e pecuária. $\mathrm{Na}$ $3^{\text {a }}$ coleta verifica-se grande amplitude nos dados com pico no ponto 3, possivelmente esteja relacionada à precipitação de chuva $(47 \mathrm{~mm})$ do dia anterior à coleta, possibilitando o arraste de sedimentos pelo escoamento superficial para o leito do arroio. De modo geral os dados de TSS são mais altos nos pontos amostrais onde a atividade antrópica é maior como foi comentado anteriormente, e, tendendo a diminuir nos pontos afastados como está demonstrado no gráfico anterior, especialmente a partir da quarta coleta de água.

É importante comentar que a $5^{\mathrm{a}}$ e $6^{\mathrm{a}}$ coletas apresentam os menores valores de TSS, possivelmente é reflexo da menor altura das chuvas na última quinzena de janeiro e primeira quinzena de fevereiro. Diferentemente das coletas comentadas anteriormente, da $1^{\mathrm{a}}$ a $4^{\mathrm{a}}$ coletas, apresentam valores mais elevados de TSS, evidentemente influenciados pelas chuvas mais intensas ocorridas neste período.

A variável está diretamente relacionada com o volume de água, com a declividade e tipo de cobertura vegetal, solo exposto e principalmente pela velocidade da água. Entretanto, nem sempre a maior vazão, que representa maior volume de água, se reflete em menor quantidade de sedimentos em suspensão, considerando-se que o maior volume de água representaria diluição deste, o contrário acontece, simplesmente pelo fato de que maior velocidade da água representa maior poder de arraste de sedimentos, ou seja, o aumento da velocidade da água tem efeito de erosão e transporte de materiais maiores do que aumento do volume da água. Sendo assim, o principal fator que determina a energia de transporte é a declividade do leito, geradora do aumento da velocidade (Schwarzbold, 2010).

\section{Considerações finais}

De um modo geral, os dados obtidos para todos os parâmetros limnológicos estudados respondem aos resultados da ação de fatores locais atuando sobre tais características na área de estudos como um todo. A forma de ocupação das áreas adjacentes ao arroio influenciaram nas características físicas, químicas e biológicas da água.

As variáveis limnológicas analisadas refletem as condições dos sistemas terrestres a cada seção dos arroios. Observou-se que as alterações mais significativas foram justamente 


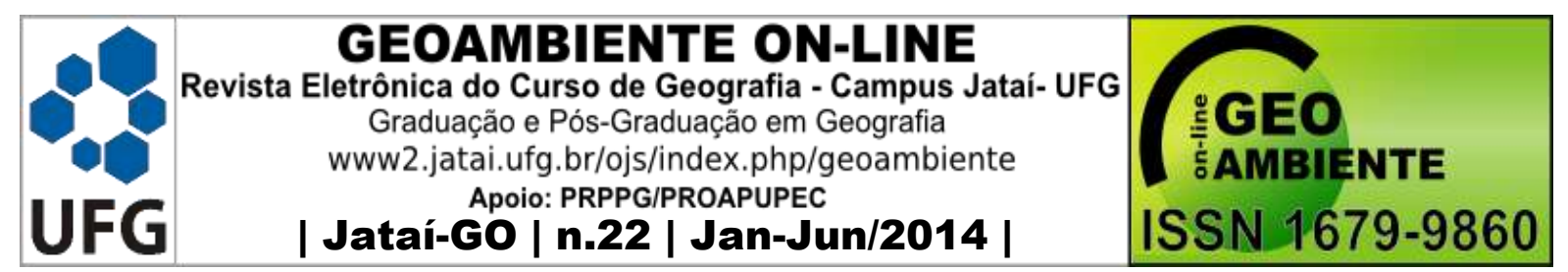

naqueles pontos (sítios-controle) alocados na periferia ou junto ao sítio urbano, locais onde os arroios recebem carga poluidora, neste caso, esgoto urbano que é lançado in natura nestes corpos d'água.

É importante notar que os dados relativos a Condutividade Elétrica, pH e TSS sofrem a mesma tendência quanto à alteração dos seus dados. Os valores tendem a serem mais baixos nos dois primeiros pontos de cólera e aumentam progressivamente nos pontos localizados a jusante, principalmente naqueles alocados junto ao perímetro urbano, com o máximo se identificados nos pontos 3 e 4; e decrescem conforme se afastam destes. Já a temperatura é influenciada por outros condicionantes, como a temperatura do ar, a hora do dia, a estação do ano.

Tomando por base os limites estabelecidos pela Resolução CONAMA N ${ }^{\circ}$ 20, de 18 de junho de 1986 e, o pH como parâmetro de qualidade da água, este, encontra-se dentro do limite estabelecido pela referida resolução. Entretanto, apresenta grande amplitude para uma microbacia, significando que as intervenções antrópicas afetam a qualidade da água, principalmente na seção junto ao perímetro urbano, mais especificamente a partir do terceiro ponto de coleta, com valor máximo no quarto ponto e decrescendo a partir do quinto ponto. Demostrando que quando se afasta da fonte poluidora a autodepuração melhora a qualidade da água.

Na classificação do uso da Terra, levando-se em consideração a geomorfologia, destaca-se que na espacialização a classe floresta corresponde a um percentual considerado satisfatório, entretanto está concentrada nas encostas mais íngremes do Rebordo do Planalto, o que é louvável considerando-se a declividade, mas, deixando a descoberto outras áreas, principalmente nas margens dos arroios e seus tributários, neste caso, a falta da mata-galeria compromete a biota destes mananciais, bem como facilita o assoreamento do leito dos rios, arroios, córregos.

As áreas de campo encontram-se alocadas principalmente na região de transição entre o Rebordo do Planalto e a Depressão Central, utilizadas para criação extensiva de gado em pequenas propriedades. Outra classe importante, a agricultura, concentra-se mais intensivamente nas planícies aluvionais dos arroios.

A variável Total de Sedimentos em Suspensão, indicam a quantidade de sedimentos em suspensão encontrada na água considerando cada seção dos arroios. Os valores obtidos 


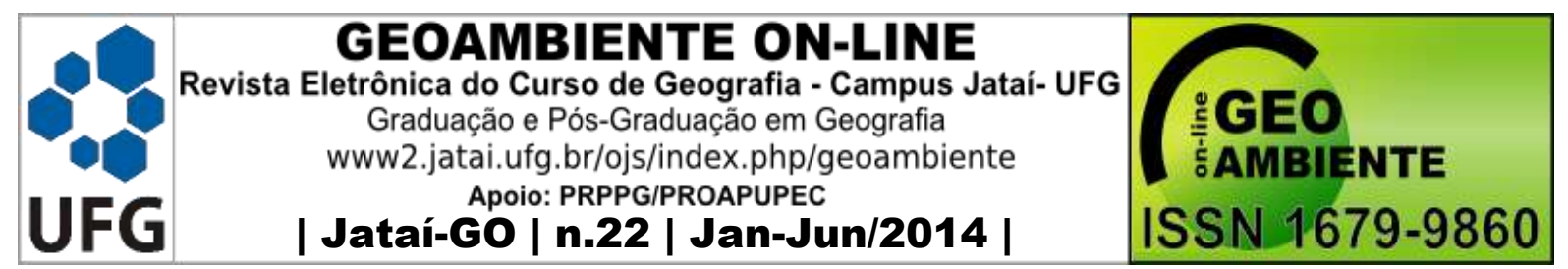

para cada amostra estão relacionados a quantidade de chuva precipitada e à freqüência destes eventos, bem como ao uso da terra na seção considerada.

Nas quatro primeiras coletas os dados de TSS estão diretamente relacionados à velocidade ao poder de arraste da água e também à época de realização das coletas, ou seja, o solo, neste período, estava mais exposto, devido ao preparo do solo para o plantio, facilitando, deste modo, o transporte de sedimentos pela água das chuvas para o leito dos arroios. As duas últimas coletas apresentaram menores valores de TSS em função da época das coletas, onde as culturas já estavam consolidadas, não existindo mais solo exposto e também em função da menor quantidade de chuvas nesta época. Por outro lado, os valores alto de TSS no ponto de controle 1 do arroio Alberti, em condições de terreno escarpado, apesar da presença de florestas ao longo do riacho na seção considerada, esta situação confere ao riacho maior velocidade a água, dando maior poder erosivo e de transporte de sedimentos.

Para execução deste trabalho, a maior dificuldade encontrada foi no sentido de que a variável vazão não pôde ser obtida, esta é uma variável extremamente importante, principalmente na análise e correlações com outras variáveis mensuradas. Recomenda-se a inclusão desta variável para execução de futuros trabalhos, pois, será possível o cruzamento com outras informações.

Outra recomendação é o planejamento adequado para o manejo do solo, de acordo com sua aptidão, obedecendo, desta forma, à declividade das vertentes e à qualidade deste solo, sem esquecer da cobertura florestal nas margens dos cursos d'água, junto às áreas onde há um intenso uso agrícola.

Com relação ao esgoto urbano recomenda-se que o mesmo seja tratado antes do lançamento nos arroios. Para tanto serão necessários estudos técnicos e financeiros executados por profissionais habilitados que viabilizem este projeto. Estas pequenas medidas contribuiriam em muito para minimização dos impactos ambientais negativos.

\section{Referências}

AGUDO, E. G. et al. Guia de coleta e preservação de amostras de água. São Paulo: CETESB, 1987.

APHA - American Public Health Association. Standard Methods for the Examination of Water and Wasterwater. 21 ed. Sprimgfield: Byrd Prepress, 2005. 


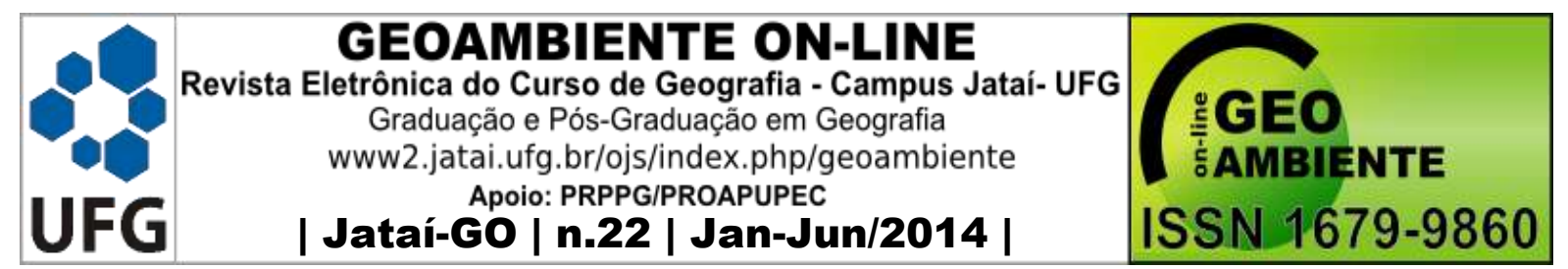

BARIANI, C. J. de M. V. Avaliação dos efeitos de atividades antrópicas por meio da análise integrada de variáveis de uso da terra e limnológicas em Itaqui, RS. 2012. 113f. Dissertação (Mestrado em Geografia) - Universidade Federal de Santa Maria, Santa Maria, 2012.

BRASIL. Resolução n. 20 de 18 de junho de 1986. Estabelece a classificação das águas do Território Nacional. Diário Oficial da República Federativa do Brasil, Brasília, DF. 30 set. 1986. Disponível em: 〈http://www.mma.gov.br/port/conama/res/res86/res2086.html〉. Acesso em: 9 fev. 2014.

COMISSÃO MUNDIAL SOBRE MEIO AMBIENTE E DESEMVOLVIEMNTO. Nosso futuro comum. 3. ed. Rio de Janeiro: Fundação Getúlio Vargas, 1991.

DIRETORIA DE SERVIÇO GEOGRÁFICO DO EXÉRCITO (DSG). Porto Alegre: Faxinal do Soturno (MI-2966/1). Porto Alegre, 1980. (Carta Topográfica: Escala 1:50.000).

ESTEVES, F. de A.; MENEZES, C. F. S. Papel da água e da limnologia na sociedade moderna. In: ESTEVES, F. de A. (Coord.). Fundamentos de limnologia. 3. ed. Rio de Janeiro: Interciência, 2011. cap. 3, p. 63-72.

ESTEVES, F. de A.; SILVA, C. P.; ALBERTONI, E. F. Ciclo da água na biosfera. In: ESTEVES, F. de A. (Coord.). Fundamentos de limnologia. 3. ed. Rio de Janeiro: Interciência, 2011. cap. 4, p. 73-81.

ESTEVES, F. de A.; SANTOS, A. M. dos. Propriedades físicas e químicas da água e sua importância limnológica. In: ESTEVES, F. de A. (Coord.). Fundamentos de limnologia. 3. ed. Rio de Janeiro: Interciência, 2011. cap. 8, p. 125-136.

GARCIA, S. M. Florestamentos compensatórios para retenção de água em microbacias. 2001. 161f. Dissertação (Mestrado em Engenharia Agrícola) - Universidade Federal de Santa Maria, Santa Maria, 2001.

IENSEN, R. E. Deterioração ambiental nos municípios da quarta colônia de imigração do Rio Grande do Sul, Brasil, em primeira (I) aproximação. 64f. Dissertação (Mestrado em Geomática) - Universidade Federal de Santa Maria, Santa Maria, 2009.

KLAMT, E.; DALMOLIN, R. S. D.; CABRAL, D. da R. Solos do Município de São João do Polêsine: características, classificação, distribuição geográfica e aptidão de uso. Santa Maria: UFSM, CCR, Departamento de Solos, 1997.

KRUPEK, R. A.; BRANCO, C. C. Z.; PERES, C. K. Estudo comparativo de parâmetros limnológicos de duas bacias de drenagem da região Centro-Sul do estado do Paraná, Sul do Brasil. Ambiência, Maringá, v. 8, n. 3, p. 821-831, 2012. 


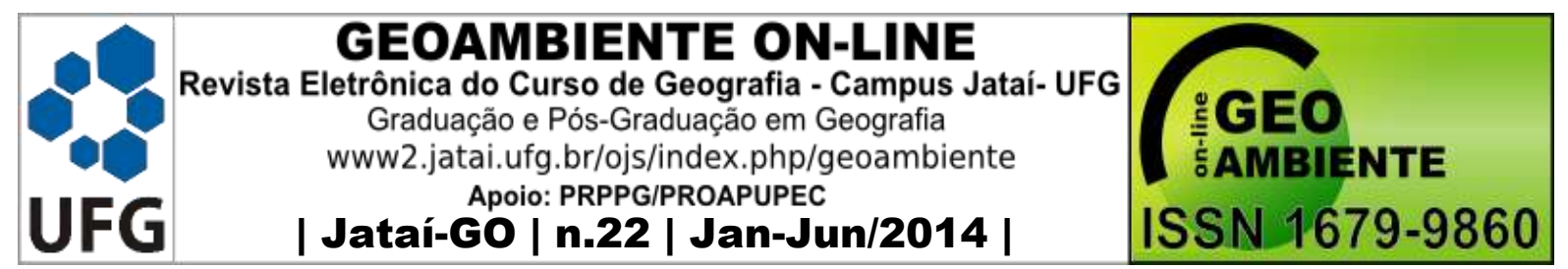

KURTZ, S. M. de J. M. Metodologia para zoneamento florestal sub-bacia hidrográfica do rio soturno (RS) (área piloto). 197f. Tese (Doutorado em Engenharia Florestal) - Universidade Federal de Santa Maria, Santa Maria, 2002.

MAROTTA, H.; SANTOS, R. O.; ENRICH-PRAST, A. Monitoramento limnológico: um instrumento para a conservação dos recursos hídricos no planejamento e na gestão urbanoambientais. Ambiente \& Sociedade, Campinas, v. XI, n. 1, p. 67-79, jan.-jun. 2008.

MÜLLER FILHO, I. L. Notas para o estudo da geomorfologia do Rio Grande do Sul, Brasil. Santa Maria: UFSM, 1970.

ODUM, E. P. Ecologia. Rio de Janeiro: Guanabara Koogan, 1988.

SCHWARZBOLD, A. Teorias ecológicas sobre rios. Ciência \& Ambiente, v. 1, n. 41, p. 0520, jul./dez. 2010.

SILVEIRA, A. L. L. da. Ciclo hidrológico e bacia hidrográfica. In: TUCCI, C. E. M. (Org.); SILVEIRA, A. L. L. da. et al. Hidrologia: ciência e aplicação. 4. ed. Porto Alegre: Editora da UFRGS/ABRH, 2012. cap. 2, p. 35-51.

TUNDISI, J. G. Água no século XXI: enfrentando a escassez. São Carlos: RiMa, IIE, 2005.

TUNDISI, J. G. Limnologia e gerenciamento integrado de recursos hídricos: avanços conceituais e metodológicos. Ciência \& Ambiente, v. 1, n. 21, p. 9-20, jul./dez. 2000. 